\title{
EVALUACIÓN Y VIVENCIA DEL DOLOR AGUDO POST OPERATORIO
}

\author{
Nicolás Mertens F. ${ }^{1}$, Paula Rodríguez B. ${ }^{2}$, María Elena Folch V. ${ }^{2}$, Gabriela Ramírez L. ${ }^{2}$ \\ $1 \quad$ Interno $7^{\circ}$ Escuela de Medicina Pontificia Universidad Católica de Chile. \\ 2 Anestesiólogo- Hospital Militar de Santiago.
}

Introducción: Más del 75\% de los pacientes sufre dolor moderado a severo en el post operatorio. Desarrollar programas de mejora continua en el manejo del dolor agudo post operatorio es una necesidad relevante. El diseño de una unidad de manejo especializada basada en calidad es una alternativa aceptada para mejorar la experiencia del paciente.

Objetivo General: El objetivo de la presente comunicación es realizar un diagnóstico actual de manejo y resultados en el dolor post operatorio en pacientes del Hospital Militar de Santiago, evaluando intensidad y vivencia en relación a éste.

Material y Métodos: Se diseñó un estudio prospectivo y observacional en pacientes mayores de 18 años, autorizado por comité de ética. Se realizó encuesta anónima estandarizada y validada de dolor agudo post operatorio a las $24 \mathrm{~h}$ post procedimiento por un equipo diferente al tratante, en forma ciega respecto de la estrategia utilizada por los tratantes. Incluyó: intensidad del dolor postoperatorio, información recibida acerca del manejo del dolor, petición de rescate, tiempo para ser atendido, interferencia con el sueño, complicaciones como náuseas y vómitos y grado de satisfacción con la analgesia. Para cuantificación del dolor se utilizó escala visual análoga (EVA) y se dividió en: leve (EVA de 1 a 3), moderado (EVA 4 a 6) y severo (EVA de 7 a 10).
Resultados: Se entrevistaron 190 pacientes al azar, 54\% hombres, mediana de rango de edad 46 a 55 años. Las cirugías más prevalentes fueron digestivas $(28,4 \%)$ y traumatológicas $(30,5 \%)$. Solamente un $20 \%$ de los pacientes no presentó dolor durante las primeras $24 \mathrm{~h}$ post procedimiento y $45,7 \%$ en la sala de recuperación. Un $64,6 \%$ tuvo dolor moderado a severo al menos una vez en el período observado, $42 \%$ en el momento inmediato post cirugía y en un $8,9 \%$ fue permanente durante las $24 \mathrm{~h}$. Sólo un $36 \%$ de los pacientes solicitó terapia de rescate, la que fue administrada antes de 15 minutos en el $83 \%$, sin embargo, a un $38 \%$ no se les explicó la estrategia anticipadamente. A pesar de esto, un $75,8 \%$ de los pacientes se manifiesta muy satisfecho del manejo recibido.

Conclusiones: El presente reporte muestra una alta satisfacción de los pacientes, pese a una baja instrucción anticipada en el manejo de su dolor y una alta incidencia de dolor moderado a severo en las primeras $24 \mathrm{~h}$ de postoperatorio. Al menos en un tercio de los pacientes la estrategia basal de analgesia fue insuficiente, demostrando necesidad de mejorar el manejo del dolor agudo post-operatorio. Este resultado no difiere de lo encontrado en la literatura. La estrategia de crear unidades especializadas en manejo de dolor agudo puede ser una alternativa importante para mejorar estor resultados. 